\title{
Analysis of the Continuous Monitored Electroencephalogram Patterns in Intensive Care Unit
}

\author{
Cheon-Sik Kim \\ Departments of Neurology, Asan Medical Center, 05505, Seoul, Korea
}

\section{집중치료실에서 지속적 뇌파검사의 뇌파 패턴 분석}

\author{
김천식
}

서울아산병원, 신경과

\begin{abstract}
The aim of this study was to detect the status of epilepticus and seizure based on the initial patterns observed in the first 30 minutes of continuous electroencephalogram (CEEG) monitoring. An cEEG was recorded digitally using electrodes applied according to the International 10 20 System. The EEG data were reviewed from January 2014 to December 2015. The baselines of the EEG patterns were characterized by lateralized periodic discharges, generalized periodic discharges, burst suppression, focal epileptiform, asymmetric background, generalized slowing, and generalized periodic discharges with a triphagic wave. The etiology was classified into five categories. The subjects of this study were 128 patients (age: $56.9 \pm 17.5$ years, male:female, 74:54). The mean CEEG monitoring duration was 5.5 \pm 5.1 (min:max, 1:33) days. The EEG pattern categories included lateralized periodic discharges $(N=7)$, generalized periodic discharges $(N=10)$, burst suppression ( $\mathrm{N}=6)$, focal epileptiform $(\mathrm{N}=19)$, asymmetric background $(\mathrm{N}=24)$, generalized slowing $(N=51)$, and generalized periodic discharges with a triphagic wave $(N=11)$. The etiological classifications of the patients with status epilepticus were remote symptomatic $(\mathrm{N}=4)$, remote symptomatic with acute precipitant $(\mathrm{N}=9)$, acute symptomatic $(\mathrm{N}=6)$, progressive encephalopathy $(\mathrm{N}=2)$, and febrile seizure $(\mathrm{N}=1)$. cEEG monitoring was found to be useful for the diagnosis of non-convulsive epileptic seizures or status epilepticus. The seizure was confirmed by the EEG pattern.
\end{abstract}

Key words: Electroencephalogram monitoring, Status epilepticus, EEG pattern

This is an Open Access article distributed under the terms of the Creative Commons Attribution Non-Commercial License (http://creativecommons.org/licenses/by-nc/4.0) which permits unrestricted non-commercial use, distribution, and reproduction in any medium, provided the original work is properly cited

Copyright @ 2017 The Korean Society for Clinical Laboratory Science. All rights reserved.
Corresponding author: Cheon-Sik Kim Departments of Neurology, Asan Medical Center, Seoul 05505, Korea

Tel: 82-2-3010-4997

Fax: 82-2-3010-6819

E-mail:dpel-kcs@daum.net

Received: July 12, 2017

Revised: July 24, 2017

Accepted: July 27, 2017

\section{서 론}

뇌파검사는 비침투성으로 뇌기능을 평가하는데 매우 유용한 검사이다. 지속적 비디오뇌파검사는 컴퓨터 기술과 업그레이 드 된 네트워크 환경, 많은 데이터를 저장할 수 있는 서버 공간 등이 발달하면서 일반검사 뿐만 아니라 집중치료실에서 다양한 환자하게 사용되고 있다. 일반 뇌파검사의 경우 기록시간이 30 분 정도로 발작 의심이 되는 환자에서 경련파를 기록하기에는
시간이 충분하지 않다. 일반 뇌파검사로 경련이 의심되는 중환 자실 환자 $50 \%$ 에서만 경련파를 찾을 수 있다고 알려져 있다[1].

지속적 비디오뇌파검사는 환자의 상태를 비디오로 기록하면 서 뇌파를 동시에 기록할 수 있어서 중첩성 또는 비발작성 중첩 성 뇌전증 환자[2], 경련이나 비정상적인 이상행동, 진정 중 뇌 파의 변화, 뇌졸중, 뇌압 상승으로 인한 코마상태 유지 약물조 절, 발작의 빈도측정, 의식의 변화 등을 진단하는데 매우 유용한 검사이다[3]. 집중치료실에서 최초로 경련이 발생했던 환자를 
대상으로 지속적비디오 뇌파검사를 24 시간 기록시 $88 \%, 48$ 시 간 기록시 $93 \%$ 의 환자에서 경련파를 찾을 수 있었다는 보고가 있다[4]. 지속적으로 30 분 동안 경련이 발생하거나 그 이상 계 속되는 발작 상태를 중첩성 뇌전증이라고 하며, 이는 응급질환 이고 신경학적으로 심한 장애 발생과 사망률이 높은 질환이다. 중첩성 뇌전증 환자의 사망률은 $22 \%$, 비발작성 중첩성 뇌전증 환자는 $48 \%$ 로 사망률이 매우 높은 질환으로 보고되고 있다 [5-7]. 집중치료실에 입원해 있는 코마환자의 8 48\%가 중첩 성 뇌전증이나 비발작성 중첩성 뇌전증이 발생했다는 보고가 있다[8,9].

집중치료실에서 지속적 비디오뇌파검사를 시행하는 목적은 뇌기능의 정확한 상태를 확인하여 중첩성 뇌전증 또는 비발작 성 중첩성 뇌전증 환자들에게 적절한 약물선택과 농도 조절로 최대한 빠른 시간에 경련을 종료시키는데 있다. 지속적 비디오 뇌파검사의 경우 최소 4 시간에서 수일간 검사가 지속되는 검사 이다. 제한된 검사장비와 고비용으로 인해 검사를 시행하지 못 하거나, 검사 도중 중단해야 하는 경우가 발생한다.

본 연구의 목적은 집중치료실에서 경련이 의심되는 환자를 대상으로 경련발생 유무와 사망률 및 경련 유발 원인 등을 파악 하고자 하였다. 또한, 제한된 이동식 뇌파 장비를 효율적으로 사 용하기 위해 초기 30 분 이내의 뇌파 패턴을 분석하여 뇌파검사 기간을 단축하거나 지속 여부를 파악하고자 하였다.

\section{재료 및 방법}

\section{1. 연구대상}

2014년 1월부터 2015년 12월까지 서울A대학병원 집중치 료실에 입원한 환자 중 지속적 비디오뇌파검사를 시행한 환자 150 명 중 128 명의 초기 30 분 뇌파의 패턴과 발작 존재 여부 및 사망률, 발병원인에 따른 뇌파 패턴을 분석하였다. 지속적 비디 오 모니터링 기간이 24시간 미만인 경우, 신생아 및 소아환자, 검사 시작부터 경련을 일으키는 뇌파 패턴을 가진 환자 22 명은 본 연구에서 제외시켰다.

\section{2. 연구방법}

1) 지속적 비디오뇌파검사

(1) 뇌파전극과 콜로디온

집중치료실에서 지속적 비디오뇌파검사를 위해 사용하는 전 극은 디스크 컵 형태의 골드 전극(Natus, Galway, Ireland)을 사용하였고, 부착용 풀은 일반 뇌파검사 시 사용하는 전극 풀을 사용하지 않고 두피에 견고하게 부착할 수 있는 콜로디온
(Mavidon, Rivera, Florida, USA)을 사용하였다. 집중치료실에 서 지속적 비디오뇌파검사 시행 시 인공산물 등을 관리하기 위 해 하루에 1 번 이상 전극 및 뇌파상태를 점검하고, 두피 마름을 방지하기 위해 뇌파용 젤을 디스크 컵 전극에 주입하였다.

(2) 뇌파 몽타주

몽타주는 두 개의 전극사이의 전위차에 의해 그려진 채널들 로 구성된 하나의 묶음이다. 집중치료실에서 지속적 비디오뇌 파검사를 위한 뇌파 몽타주는 국제표준 10 20 시스템에 따른 이중 바나나몽타주(double banana montage, Fp1-F7, F7-T7, T7-P7, P7-O1, Fp2-F8, F8-T8, T8-P8, P8-O2, $\mathrm{Fz}-\mathrm{Cz}, \mathrm{Cz}-\mathrm{Pz}$ )로 부중심부 체인(parasagital chain)으로 구성 하였다.

(3) 비디오뇌파검사 장비

지속적 비디오뇌파검사장비(Stellate, Quebec, Canada)는 비디오가 동기화 되어 있어서 발작현상, 환자의 이상행동 등을 실시간으로 관찰 할 수 있도록 하였고, 이전 시간에 기록된 데이 터들을 검토할 때도 뇌파기록과 비디오가 동시에 녹화되면서 이전 데이터를 검토할 수 있도록 하였다.

(4) 네트워크 환경

집중치료실에 셋팅된 지속적 비디오뇌파검사는 네트워크를 통하여 뇌파 판독실에서 실시간으로 판독이 가능할 수 있도록 하였고, 기록 중 발작이나 이상행동 시 환자의 상태에 따라 항뇌 전증약이나기타 필요한약물을수시로 조정할 수 있도록 하였다.

\section{2) 뇌파 패턴 분석}

모든 환자의 처음 30 분 이내의 뇌파 패턴을 분석하였고, 뇌파 판독은 신경과 전문의가 하였다. 뇌파의 패턴은 주기적 방전파, 전반적 주기적 방전파, 버스트 억제파, 초점 뇌전증파, 비대칭 배경파, 전반적 서파, 삼상성 형태의 일반화 된 주기적 방전파 등 7 가지 범주로 분류하였다. 지속적 비디오뇌파검사를 시행한 환자의 처음 30 분에 나타난 주요 뇌파 패턴에 따라 2 가지 환자 군으로 분류하였다[10]. 고위험군은 국소화 된 주기적 방전파, 전반적 주기적 방전파, 버스트 억제파, 초점 뇌전증파로 분류하 였고, 저위험군은 비대칭 배경파, 전반적 서파, 삼상성 형태의 일반화 된 주기적 방전파로 분류하였다.

\section{3) 원인에 따른 중첩성 뇌전증 분석}

중첩성 뇌전증을 원인에 따라 5가지 형태로 분류하였다[11]. 1) 원발성 증상성(remote symptomatic, RS): 신경학적 손상은 있으나 특별한 유발요인 없이 경련이 발생한 경우, 2) 급성원발 성 증상성(remote symptomatic with acute precipitant, 
$\mathrm{RSAP})$ : 경련을 일으킬 수 있는 원인과 함께 신경학적 손상이 동 반된 경우, 3) 급성 증상성(acute symptomatic, $\mathrm{AS}$ ): 경련과 동 시에 급격한 신경학적 손상이 발생한 경우, 4) 진행성 뇌병증 (progressive encephalopathy, $\mathrm{PE}$ ): 경련과 동반된 신경학적 으로 진행성 질환이 동반된 경우, 5) 열성경련(febrile seizure, $\mathrm{FS})$ : 고열이 동반된 경련으로 분류하였다. 128 명의 환자 중 중 첩성 뇌전증이 발생한 22 명의 원인에 따른 뇌파의 패턴을 분석 하였다.

\section{4) 통계처리}

통계처리는 SPSS version 21.0 (SPSS Inc., Chicago, IL, USA)을 사용하였다. 발작 유무에 따른 두 그룹간의 비교는 독립 표본 t-검정으로 하였고, 중첩성 뇌전증이 발생한 22 명의 뇌파 패턴별 사망률을 분석하였다. 발작 유무에 따른 각 뇌파 패턴을 통하여 발작 발생 위험도를 회귀분석 이분형 로지스틱을 통하 여 분석하였다.

\section{결 과}

집중치료실에서 지속적 비디오뇌파검사를 시행한 128 명의 환자 나이는 발작이 없었던 군은 $57 \pm 17.3$ 이였고, 발작이 있었 던 군은 $54.8 \pm 19.0$ 였다. 남녀 비율은 발작이 없었던 군은 남자
가 많았고, 발작이 있었던 군은 여자가 많았으며, 이는 통계적으 로 유의하였다 $(p=0.038)$. 지속적 비디오뇌파검사를 시행한 기 간은 발작이 있었던 군과 없었던 군 사이에 통계적으로 유의성 은 없었으나 $(p=0.353)$, 발작이 있었던 군의 검사기간이 1 일 정 도 길었다(Table 1).

초기 30 분 이내의 뇌파 패턴을 분석한 결과 발작이 없었던 군 $(\mathrm{N}=106)$ 은 전반적 서파( $47.1 \%)$ 가 가장 많았고, 비대칭적 뇌파 패턴(21.7\%)이 많았다. 발작이 있었던 군은 초점 뇌전증 파형 (27.2\%), 전반적 주기적 방전파(22.7\%), 버스트 억제파(18.1\%) 가 많았다. 삼상성 형태의 일반화 된 주기적 방전파와 비교해 경 련이 발생할 위험도는 버스트 억제파의 경우 18 배,주기적 방전 패턴은 12 배 높았다(Table 2).

22 명의 경련군 중 사망자는 9 명으로 $40.9 \%$ 였다. 초기 30 분 이내의 뇌파 패턴과 관련하여 사망률을 분석하면 주기적 방전 파 7명 중 2 명이 사망하였고, 전반적 주기적 방전파는 10 명중 2 명, 버스트 억제파는 6명 중 3명, 초점 뇌전증 파는 19명 중 2명 이 사망하였으며, 사망자 모두 고위험군 환자들 이었다(Table 3). 중첩성 뇌전증 환자의 원인은 원발성 증상성 $(\mathrm{N}=4)$, 급성원 발성 증상성 $(\mathrm{N}=9)$, 급성 증상성 $(\mathrm{N}=6)$, 진행성 뇌병증 $(\mathrm{N}=2)$, 열 성경련 $(\mathrm{N}=1)$ 이었다(Table 4).

Table 1. Demographics of patients of continuous EEG monitoring

\begin{tabular}{lccc}
\hline & Seizure Absent $(\mathrm{N}=106)$ & Seizure Present $(\mathrm{N}=22)$ & $p$-value \\
\hline Age (year) & $57 \pm 17.3$ & $54.8 \pm 19.0$ & 0.855 \\
Sex (male:female) & $67: 39$ & $7: 15$ & $0.038^{\star}$ \\
Height (cm) & $164.6 \pm 9.7$ & $159.9 \pm 10.8$ & 0.101 \\
Weight (kg) & $62.0 \pm 13.1$ & $53.7 \pm 10.8$ & 0.007 \\
EEG Duration (day) & $5.3 \pm 4.8$ & $6.1 \pm 6.7$ & 0.353 \\
\hline
\end{tabular}

$p<0.05, p$-values were calculated by t-test, ${ }^{*}$ chi-square test.

Abbreviation: EEG, electroencephalogram.

Table 2. Rate of electrographic seizures as a function of initial continuous EEG pattern

\begin{tabular}{lcccc}
\hline \multicolumn{1}{c}{ Initial EEG recording } & $\begin{array}{c}\text { Seizure absent } \\
(\mathrm{N}=106),(\%)\end{array}$ & $\begin{array}{c}\text { Seizure present } \\
(\mathrm{N}=22),(\%)\end{array}$ & $\begin{array}{c}\text { EXP }(\beta) \\
(95 \% \mathrm{Cl})\end{array}$ & $p$-value \\
\hline Lateralized periodic discharges & $3(2.8)$ & $4(18.1)$ & $12.0(0.61 \sim 45.90)$ & 0.043 \\
Generalized periodic discharges & $5(4.7)$ & $5(22.7)$ & $6.0(0.55 \sim 29.09)$ & 0.047 \\
Burst suppression & $2(1.9)$ & $4(18.1)$ & $18.0(0.80 \sim 65.65)$ & 0.034 \\
Focal epileptiform & $13(12.3)$ & $6(27.2)$ & $4.8(0.27 \sim 10.58)$ & 0.171 \\
Asymmetric background & $23(21.7)$ & $1(4.5)$ & $0.30(0.01 \sim 2.18)$ & 0.523 \\
Generalized slowing & $50(47.1)$ & $1(4.5)$ & $0.18(0.00 \sim 0.98)$ & 0.240 \\
GPD with triphagic wave & $10(9.4)$ & $1(4.5)$ & 1 & 0.001 \\
\hline
\end{tabular}

$p$-values were calculated by logistic regression.

Abbreviation: $95 \% \mathrm{CI}$, 95\% coefficients interval; GPD, generalized periodic discharges. 
Table 3. Outcomes of initial EEG pattern in patients with status epilepticus ( $\mathrm{N}=22)$

\begin{tabular}{lccc}
\hline \multicolumn{1}{c}{ EEG pattern } & Died & New deficit & RTB \\
\hline Lateralized periodic discharges $(\mathrm{N}=4)$ & 2 & 2 & \\
Generalized periodic discharges $(\mathrm{N}=5)$ & 2 & 1 & 2 \\
Burst suppression $(\mathrm{N}=4)$ & 3 & 1 & \\
Focal Epileptiform $(\mathrm{N}=6)$ & 2 & 3 & 1 \\
Asymmetric background $(\mathrm{N}=1)$ & & & 1 \\
Generalized slowing $(\mathrm{N}=1)$ & & & 1 \\
GPD with triphagic wave $(\mathrm{N}=1)$ & & & 1
\end{tabular}

Abbreviation: RTB, return to baseline.

\section{고 찰}

지속적 비디오뇌파검사의 적응증은 발작성 또는 비발작성 중첩성 뇌전증, 비정상적인 이상행동, 코마 세라피, 심정지, 중 추 신경계 감염, 경막하 혈종 및 허혈성 뇌졸중, 코마 환자 등 다 양하다[12-14].

집중치료실에서 지속적 비디오뇌파검사를 시행한 환자의 $8 \sim 35 \%$ 가 중첩성 뇌전증이 발생했다는 보고가 있고 $[15,16]$, 많게는 48 68\%까지 보고되고 있다[1,6]. 본 연구는 집중치료 실에 입원한 환자 중 지속적 비디오뇌파검사를 시행한 150 명 중 128 명을 대상으로 분석하였고, 이 중 발작성 또는 비발작성 중첩성 뇌전증을 가진 환자는 22 명으로 전체 환자의 $17.1 \%$ 였 다. 이전 보고에 의하면 비발적성 중첩성 뇌전증 환자는 $4 \%$ 48로 보고되고 있다. 본 연구에서는 중첩성 뇌전증 환자 22 명중 13 명이 비발작성 중첩성 뇌전증 환자로 59\%였고[6,17], 이는 이전의 보고보다 많았다. 중첩성 뇌전증을 일으키는 가장 흔한 원인은 뇌혈관질환, 뇌종양, 감염, 항뇌전증 약물조절 실패, 진 행성 염증 환자 등에서 많이 발생한다고 알려져 있다[18].

본 연구에서 비발작성 중첩성 뇌전증 환자가 많았던 이유는 급성뇌염 환자, 헤르페르 바이러스 감염 환자가 많았고, 이로 인 해 이전 보고보다 많은 것으로 생각되어진다. 비발작성 중첩성 뇌전증은 환자가 외관상 특별한 움직임이나 경련증상이 없기 때문에 지속적 비디오뇌파검사를 진행하지 않았다면 중첩성 뇌 전증에 대한 치료를 할 수 없는 상황으로 환자에게 심각한 신경 학적 손상을 가져올 수 있다.

중첩성 뇌전증은 지속적 비디오뇌파검사 기간이 길수록, 성 인보다는 소아가 사망률이 높은 것으로 알려져 있다[19,20]. 본 연구에서 중첩성 뇌전증을 가진 환자의 평균 비디오뇌파검사

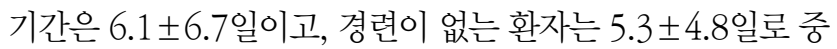
첩성 뇌전증을 가진 환자의 검사 기간이 하루 정도 길었다. 중첩 성 뇌전증을 가진 22 명의 환자 중 9 명이 사망하였고, 이들의 모 니터링 뇌파검사 기간은 $12.3 \pm 9.8$ 일이었다. 본 연구에서도 이
Table 4. Comparison of two groups of patients with status epilepticus according to etiology $(\mathrm{N}=22)$

\begin{tabular}{ccc}
\hline Etiology & High risk group $(\mathrm{N}=18)$ & Low risk group $(\mathrm{N}=4)$ \\
\hline RS & 3 & 1 \\
RSAP & 8 & 1 \\
AS & 5 & 1 \\
PE & 1 & 1 \\
FS & 1 & 0 \\
\hline
\end{tabular}

Abbreviation: RS, remote symptomatic; RSAP, remote symptomatic with acute precipitant; AS, acute symptomatic; $\mathrm{PE}$, progressive encephalopathy; FS, febrile seizure.

전에 보고된 연구와 동일하게 비디오뇌파검사 기간이 길수록 사망률이 높았으며, 이는 치료기간이 길어질수록 환자 신체 장 기의 기능저하, 체내 대사성 장애, 감염 등이 사망률을 높였으리 라 생각되어진다.

초기 30분 이내의 뇌파 패턴 중 저위험군인 비대칭성 파형, 전반적 서파, 전반적 주기적 삼상성파형은 중첩성 뇌전증 발생 위험성은 낮았고, 고위험군인 주기적 방전파, 전반적 주기적 방 전파, 버스트 억제파, 초점 뇌전증 파형의 중첩성 뇌전증 발생 위험성은 정상 뇌파 패턴과 비교 시 높았다. 보고에 의하면 주기 적 방전파, 버스트 억제성파, 초첨 뇌전증파 뇌파 패턴을 가진 환자가 경련을 일으키는 비율이 높다고 알려져 있고[8,10], 본 연구에서도 고위험성군이 중첩성 뇌전증을 일으키는 비율이 높 았다. 발작이 발생된 환자군이 상대적으로 적어 검사 기간과 성 별을 통하여 보정된 값 또한 고위험성군에서 중첩성 뇌전증을 일으키는 위험도가 높았다. 집중치료실에서 지속적 비디오뇌 파검사의 경우 1 일에서 최장 33 일까지 검사를 진행하였고, 이 는 경련 유무을 확인하기 위한 목적이 많다. 지속적 비디오뇌파 모니터링 검사는 비용이 비싸고, 제한된 장비로 인해 검사대기 를 지연시킨다. 전체 환자 128 명 중 전반적 서파 환자는 51 명 중 1 명, 비대칭적 배경파 환자 24 명 중 1 명의 환자에서 경련이 발 생 하였다. 저위험군의 경련 발생률은 낮았으나, 고위험군의 경 련발생률은 $50 \%$ 이상으로 매우 높았다. 이는 초기 뇌파 패턴 확 인으로 환자의 경련발생 예측이 가능하고, 저위험군과 고위험 군에 따라 장기간의 지속적 비디오뇌파모니터링 기간이 줄어들 수 있으리라 생각된다.

원인별 지속적 중첩성 뇌전증은 급성원발성 증상성이 9명으 로 가장 많았고, 급성증상성 6 명, 원발성 증상성 4 명, 진행성 뇌 병증 2 명, 열성경련 1명이었다. 급성으로 발생한 15 명 중 5 명은 뇌졸중, 4 명이 뇌염, 3 명이 헤르페스 바이러스 감염, 2 명이 박테 리아 감염, 1 명이 급성심정지 환자였고, 이 중 사망자는 6 명으 로 사망률은 $40 \%$ 였다. 급성환자의 15 명 중 8 명은 8 월에서 2 월 사이 초기 인플레인자 바이러스나 헤르페스 바이러스 의심으로 
시작하여 초기 치료가 늦어짐으로 인해 사망이나 신경학적 손 상이 심각한 상태까지 이르는 경우가 많았다.

이 연구의 제한점은 전체 환자 중 중첩성 뇌전증이 발생한 환 자가 22 명으로 연구대상 환자수가 적었고, 특정 뇌파 패턴의 환 자가 상대적으로 적어 통계적 분석에 제한점이 있었다. 또한, 사 용되는 약물 조절에 따라 지속적 비디오뇌파 검사 기간이 차이 가 있을 수 있으리라 생각되나 약물 조절과 관련한 뇌파의 변화 는 분석하지 못했다. 이러한 연구의 한계점에도 불구하고 특정 뇌파 패턴이 경련 발생 유무를 미리 예측할 수 있는 지표가 될 수 있고, 지속적 비디오뇌파검사를 통하여 초기 뇌파패턴이 중첩 성 뇌전증 환자를 구별할 수 있는 예측인자가 될 수 있었다.

\section{요 약}

이 연구의 목적은 중첩성 뇌전증을 발견하고, 처음 기록된 30 분 뇌파 패턴을 통하여 경련 가능성을 알아보고자 한다. 국제표 준 10 20법을 통하여 전극을 부착하였다. 2014년 1월부터 2015년 12월까지 중환자실에 입원한 경련 의심 환자를 대상으 로 하였다. 뇌파의 패턴은 주기적 방전파, 전반적 주기적 방전 파, 버스트 억제파, 초점 뇌전증파, 비대칭 배경파, 전반적 서파, 삼상성 형태의 일반화 된 주기적 방전파 등 7 가지 범주로 분류 하였다. 원인별 분류는 5 가지 범주로 구분하였다. 전체 128 명 중 평균 나이는 56.9 \pm 17.5 였고, 남:여 비율은 $74: 54$ 명이였다. 평균 뇌파검사 기간은 $5.5 \pm 5.1$ 일 이었고 최장 33 일 이였다. 주 기적 방전파( $\mathrm{N}=7)$, 전반적 주기적 방전파 $(\mathrm{N}=10)$, 버스트 억제 파 $(\mathrm{N}=6)$, 초점 뇌전증파 $(\mathrm{N}=19)$, 비대칭 배경파 $(\mathrm{N}=24)$, 전반적 서파(N=51), 3 상 형태의 일반화 된 주기적 방전파 $(\mathrm{N}=11)$ 이었 다. 중첩성 뇌전증 환자의 원인은 원발성 증상성 $(\mathrm{N}=4)$, 급성원 발성 증상성 $(\mathrm{N}=9)$, 급성 증상성 $(\mathrm{N}=6)$, 진행성 뇌병증 $(\mathrm{N}=2)$, 열 성경련 $(\mathrm{N}=1)$ 이었다. 지속적 뇌파모니터링 검사는 중첩성 뇌전 증을 발견하는데 유용한 검사이고, 뇌파 패턴을 통하여 경련 발 생 유무를 확인할 수 있었다.

\section{Acknowledgements: None \\ Funding: None \\ Conflict of interest: None}

\section{REFERENCES}

1. Pandian JD, Cascino GD, So EL, Manno E, Fulgham JR. Digital video-electroencephal-ographic monitoring in the neurological-neurosurgical intensive care unit: clinical features and outcome. Arch Neurol. 2004;61(7):1090-1094.

2. Amantini A, Carrai R, Lori S, Peris A, Amadori A, Pinto F. et al. Neurophysiological monitoring in adult and pediatric intensive care. Minerva Anestesiol. 2012;78(9):1067-1075.

3. Herman ST, Abend NS, Bleck TP, Chapman KE, Drislane FW, Emerson RG. et al. Consensus statement on continuous EEG in critically ill adults and children, part I: Indications. J Clin Neurophysiol. 2015;32(2):87-95.

4. Claassen J, Mayer SA, Kowalski RG, Emerson RG, Hirsch LJ. Detection of electrographic seizures with continuous EEG monitoring in critically ill patients. Neurology. 2004;62(10): $1743-1748$.

5. Treiman DM, Meyers PD, Walton NY, Colling C, Rowan AJ, Handforth A. et al. A comparison of four treatments for generalized convulsive status epilepticus. Veterans Affairs Status Epilepticus Cooperative Study Group. N Engl J Med. 1998; 339(12):792-798.

6. DeLorenzo RJ, Waterhouse EJ, Towne AR, Boggs JG, Ko D, DeLorenzo GA. et al. Persistent nonconvulsive status epilepticus after the control of convulsive status epilepticus. Epilepsia. 1998;39(8):833-840.

7. Brophy GM, Bell R, Claassen J, Alldredge B, Bleck TP, Glauser T. et al. Guidelines for the evaluation and management of status epilepticus. Neurocrit Care. 2012;17(1):3-23.

8. Claassen J, Jette N, Chum F, Green R, Schmidt M, Choi H,Jirsch J. et al. Electrographic seizures and periodic discharges after intracerebral hemorrhage. Neurology. 2007;69(13):1356-1365.

9. Vespa PM, Nuwer MR, Nenov V, Ronne-Englstrom E, Hovda DA, Bergsneider M. et al. Increased incidence and impact of nonconvulsive and convulsive seizures after traumatic brain injury as detected by continuous electroencephalographic monitoring. J Neurosurg. 1999;91(5):750-760.

10. Claassen J, Mayer SA, Kowalski RG, Emerson RG, Hirsch LJ. Detection of electrographic seizures with continuous EEG monitoring in critically ill patients. Neurology. 2004;62(10): $1743-1748$.

11. Maytal J, Shinnar S, Moshe S, Alvarez LA. Low morbidity and mortality of status epilepticus in children. Pediatrics. 1989; 83(3):323-331.

12. Bernard SA, Jones BM, Horne MK. Clinical trial of induced hypothermia in comatose survivors of out-of-hospital cardiac arrest. Ann Emerg Med. 1997;30(2):146-153.

13. Badjatia N, Kowalski RG, Schmidt JM, Voorhees ME, Claassen J, Ostapkovich ND. et al. Predictors and clinical implications of shivering during therapeutic normothermia. Neurocrit Care. 2007;6(3):186-191.

14. Plestis KA, Loubser P, Mizrahi EM, Kantis G, Jiang ZD, Howell JF. Continuous elec -troencephalographic monitoring and selective shunting reduces neurologic morbidity rates in carotid endarterectomy. J Vasc Surg. 1997;25(4):620-628.

15. Jordan KG. Neurophysiologic monitoring in the neuroscience intensive care unit. Neurol Clin. 1995;13(3):579-626.

16. Towne AR, Waterhouse EJ, Boqqs JG, Garnett LK, Brown AJ, Smith JR. et al. Prevalence of nonconvulsive status epilepticus in comatose patients. Neurology. 2000;54(2):340-345.

17. Shafi MM, Westover MB, Cole AJ, Kilbride RD, Hoch DB, Cash SS. Absence of early epileptiform abnormalities predicts lack of 
seizures on continuous EEG. Neurology. 2012;79(17):1796-1801.

18. Trinka E, Hofler J, Zerbs A. Causes of status epilepticus. Epilepsia. 2012;53(4):127-138.

19. Osorio I, Reed RC. Treatment of refractory generalized tonic-clonic status epilepticus with pentobarbital anesthesia after high-dose phenytoin. Epilepsia. 1989;30(4):464-471.

20. Sahin M, Menache CC, Holmes GL, Riviello JJ. Outcome of severe refractory status epilepticus in children. Epilepsia. 2001;42(11):1461-1467. 